\title{
PEMBERDAYAAN PERAN KADER MELALUI POSYANDU REMAJA PLUS KIE KESEHATAN REPRODUKSI DI POSYANDU REMAJA KELURAHAN PENYENGAT RENDAH KOTA JAMBI
}

\author{
Ruwayda $^{1}$, M.Dody Izhar ${ }^{2}$ \\ ${ }^{1}$ Jurusan Kebidanan Poltekkes Kemenkes Jambi, ${ }^{2}$ Fak. Kedokteran \& Ilmu Kesehatan \\ Universitas Jambi \\ E-mail: ruwayda@poltekkesjambi.ac.id
}

\begin{abstract}
The implementation integrated health center of adolences begins in 2018 at Aur Duri Primary Health Care, the number of adolescent visits has decreased due to one of them being established and there is no specific method in providing information and education communication (IEC) reproductive health. The target activities are 30 adolescents in Penyengat Rendah from April to June 2019. These community service activities through 3 stages of activity: the preimplementation stage determining and obtaining a response letter from partners, arranging cooperation and determining goals activities, determine fun and flexible methods, determine activities which include lectures, discussion of Buzz Group methods and IEC practices. The implementation phase includes the provision of information about IEC through discussions using the Buzz Group and IEC practices. The post-implementation phase evaluates the knowledge and skills in providing IEC. The results of knowledge tests showed differences in the mean knowledge before and after using the Buzz Group of 3.133. The conclusion was level of achievement the target good, and adolescents feel the many benefits received increasing knowledge and skills of giving IEC to their peers. It is recommended for Primary Health care can develop this activity in other integrated health center of adolescent
\end{abstract}

Keywords: Integrated Health Center Adolescen, Information and education communication

\section{PENDAHULUAN}

Sistem Kesehatan Nasional (SKN) telah merumuskan salah satu tujuan pembangunan nasional yaitu tercapainya kemampuan hidup sehat. Sistem Kesehatan Nasional (SKN) 2009 yang dikeluarkan oleh Kementerian Kesehatan Republik Indonesia sebagai penyempurnaan dari SKN sebelumnya merupakan bentuk dan cara penyelenggaraan pembangunan kesehatan yang dilakukan oleh pemerintah bersama seluruh elemen bangsa dalam rangka untuk meningkatkan tercapainya pembangunan kesehatan dalam mewujudkan derajat kesehatan yang setinggitingginya. Derajat kesehatan masyarakat merupakan salah satu indikator keberhasilan pembangunan nasional. 


\section{GEMASSIKA: Jurnal Pengabdian Kepada Masyarakat}

Vol. 4 No. 2 November 2020

Masa remaja merupakan masa storm dan stress karena remaja mengalami banyak tantangan baik dari diri mereka sendiri (biopsychosocial factors) ataupun lingkungan (environmental factors) apabila remaja tidak memiliki kemampuan untuk menghadapi berbagai tantangan tersebut mereka dapat berakhir pada berbagai masalah kesehatan yang begitu kompleks sebagai akibat dari perilaku berisiko yang mereka lakukan.

Berdasarkan hasil survei kesehatan berbasis sekolah di Indonesia tahun 2015 (GSH) dapat terlihat gambaran faktor risiko kesehatan pada pelajar usia 12-18 tahun secara nasional sebanyak 41,8 \% laki-laki dan 4,1\% perempuan mengaku pernah merokok, $32,82 \%$ diantara perokok pertama kali pada umur $<13$ tahun. Perilaku seks pra nikah tentunya memberikan dampak yang luas pada remaja terutama berkaitan dengan penularan penyakit menular seksual dan kehamilan tidak diinginkan serta aborsi

Pelayanan Kesehatan Peduli Remaja (PKPR) diberikan kepada semua remaja dilaksanakan di dalam dan di luar gedung untuk perorangan atau kelompok. Pengembangan PKPR di Puskesmas sampai tahun 2017 sudah mencapai 5015 puskesmas yang tersebar di 514 Kabupaten/Kota. Puskesmas PKPR memberikan layanan mulai dari KIE, konseling, pembinaan konselor sebaya, layanan klinis/medis dan rujukan serta pemberdayaan remaja dalam bentuk keterlibatan aktif dalam kegiatan kesehatan.

Data BPS tahun 2015 tentang angka partisipasi murni tingkat pendidikan SMP sebesar 77,69 \% dan SMA 59,85\% artinya mereka berada di sekolah dan mendapatkan pembinaan kesehatan melalui UKS tetapi kadang kala kegiatan tersebut belum cukup untuk memenuhi kebutuhan remaja akan kesehatannya. Dari data menunjukkan sekitar $23 \%$ usia SMP dan $41 \%$ usia SMA tidak bersekolah artinya mereka tidak mendapatkan pembinaan kesehatan seperti anak-anak yang bersekolah. Hal ini menunjukkan begitu banyak jumlah remaja yang membutuhkan tempat yang dapat diakses dengan mudah untuk menyelesaikan dan mendiskusikan masalah kesehatannya selain dari fasilitas kesehatan yang sudah tersedia. Pembentukan posyandu remaja diharapkan dapat menjadi wadah untuk menfasilitasi remaja dalam memahami masalah kesehatan remaja, menemukan alternatif pemecahan masalah, membentuk kelompok dukungan remaja, memperluas jangkauan puskesmas PKPR terutama bagi remaja daerah yang memiliki keterbatasan akses.

Hasil SDKI (2012) menunjukkan bahwa pengetahuan remaja tentang kesehatan reproduksi belum memadai. Hanya $35 \%$ 
remaja perempuan dan 31,2\% remaja lakilaki umur 15-19 tahun mengetahui bahwa perempuan dapat hamil dengan satu kali berhubungan seksual. Sebanyak 41,2 \% perempuan dan 55,3\% laki-laki umur 1519 tahun mengetahui cara penularan HIVAIDS dapat dikurangi jika berhubungan seks hanya dengan seseorang yang tidak memiliki pasangan lain. $46 \%$ perempuan dan 60,8 \% laki-laki umur 15-19 tahun mengetahui bahwa penularan HIA/AIDS dapat dikurangi dengan menggunakan kondom. Hanya 9,9\% perempuan dan 10,6 \% laki-laki umur 15-19 tahun memiliki pengetahuan komprehensif mengenai HIV/AIDS (Kemenkes, 2015)

Remaja umur 15-19 tahun lebih suka berdiskusi/curhat mengenai masalah kesehatan reproduksi kepada teman sebayanya seperti yang ditunjukkan dalam SDKI (2012) dimana sebesar 57,1 \% lakilaki dan 57,6 \% perempuan berdiskusi/ curhat mengenai kesehatan reproduksi dengan temannya. Sementara itu remaja umur 15-19 tahun menyukai bila sumber informasi kesehatan reproduksi diperoleh dari teman sebaya $(33,3 \%$ laki-laki dan 19,9\% perempuan), guru (29,6\% laki-laki dan 31,2 $\%$ perempuan), ibu (12,7 \% laki-laki dan 40 $\%$ perempuan) tenaga kesehatan $(2,6 \%$ lakilaki dan 35,7 \% perempuan). Jenis informasi yang sering diperoleh remaja adalah bahaya penyalahgunaan NAPZA, bahaya minum minuman beralkohol dan tentang HIV AIDS termasuk penggunaan kondom untuk mencegah penularannya.

Pada posyandu remaja KIE yang diberikan mencakup pemberian informasi tentang organ reproduksi remaja, pubertas, proses kehamilan, menstruasi, $\mathrm{KB}$, penyakit menular seksual, gender dan pendewasaan usia perkawinan. HIV/AIDS mencakup pemberian informasi seputar penularan, pencegahan dan gejala (Kemenkes, 2018).

Pelaksanaan Posyandu Remaja di Kota Jambi baru dimulai tahun 2018 dan baru terlaksana di satu puskesmas yaitu Puskesmas Aur Duri. Sasaran remaja di Kota Jambi usia 10-18 tahun sebanyak 276.163 orang. Di Puskesmas Aur Duri sasaran remaja 3435 orang. Jumlah kunjungan remaja ke posyandu dalam tiga bulan terakhir mengalami penurunan dari 60 (100\%) menjadi 45 (75 \%) pada bulan april 2019. Angka partisipasi kunjungan remaja ke posyandu menunjukkan minat remaja untuk berperan serta dalam posyandu, keikutsertaan dalam berbagai kegiatan dan pemeriksaan yang ada di posyandu tersebut. Menurunnya partisipasi remaja dikarenakan posyandu ini baru berdiri dan belum ada metode khusus dalam pemberian komunikasi Informasi dan edukasi 
(KIE) khususnya kesehatan reproduksi (Puskesmas Aur Duri, 2019).

\section{MASALAH, TARGET DAN LUARAN}

Permasalahan yang dihadapi pada Mitra adalah:

a. Belum tersosialisasikannya program Posyandu remaja Plus KIE di kalangan remaja usia 10-19 tahun di wilayah Puskesmas Aur Duri sehingga angka partisipasi remaja ke Posyandu masih dibawah target.

b. Belum adanya kegiatan yang berkaitan dengan peningkatan pengetahuan kader Posyandu tentang KIE khusunya kesehatan reproduksi remaja

c. Belum adanya kegiatan berkaitan dengan peningkatan keterampilan bagi kader posyandu dalam memberikan KIE kepada remja sebagai sasaram

Target luaran yang dinginkan adalah:

a. Remaja mengenal program posyandu remaja dan mendapatkan program plus KIE konseling kesehatan reproduksi remaja

b. Kader Posyandu remaja dapat memahami pengetahuan tentang KIE kesehatan reproduksi remaja sehingga dapat memberikan informasi yang baik dan benar c. Kader Posyandu remaja dapat mempraktikkan teknik KIE kesehatan reproduksi dengan baik.

d. Terlaksananya KIE plus pada kegiatan posyandu remaja

\section{METODE PELAKSANAAN}

Pengabdian kepada masyarakat dilaksanakan pada bulan April-Juni tahun 2019 . Peserta kegiatan pengabmas ini adalah kader posyandu dan remaja yang berminat menjadi kader posyandu remaja sebanyak 30 orang. Rangkaian kegiatan pengabdian kepada masyarakat meliputi 3 tahap yaitu

Tahap Pra pelaksanaan meliputi 1) Menentukan danmendapatkan surattanggapan dari mitra yaitu Kepala Puskesmas Aur Duri dan Lurah Kelurahan Penyengat Rendah Kota Jambi, menyusun MoU kerjasama dan terdapat manfaat yang saling menguntungkan; 2) menentukan tujuan kegiatan dalam rangka meningkatkan partisipasi remaja ke posyandu; 3) menentukan metode yang menyenangkan bagi kader dan calon kader remaja yang fleksibel metode KIE pada program kegiatan posyandu; 4) menentukan aktivitas yang meliputi ceramah, diskusi dengan metode Buzz Group dan praktik KIE kesehatan reproduksi oleh konselor sebaya.5) Pengisian Kuesioner Pre Test 
Tahap Pelaksanaan sebagai berikut: (1) pemberian materi/informasi tentang KIE kesehatan reproduksi pada kader remaja yang menjadi sasaran sehingga dapat meningkatkan pengetahuan dan informasi kepada kader remaja tentang permasalahan remaja yang dihadapi dan mengetahui cara menghadapi masalah tersebut; (2) memberikan materi melalui diskusi menggunakan metode Buzz Group sehingga semua materi tersampaikan dengan baik dan menyenangkan; memberikan pelatihan tentang praktik Komunikasi Informasi dan Edukasi (KIE) kesehatan reproduksi yang bertujuan agar kader remaja mampu menjadi seorang konselor sebaya.

Tahap Pasca Pelaksanaan sebagai berikut: (1) mengevaluasi pemahaman pengetahuan kader remaja tentang materi yang disampaikan; (2) mengevaluasi ketrampilan remaja dalam memberikan KIE kesehatan reproduksi terhadap teman sebayanya. 3) Mengisi kuesioner post test.

\section{HASIL PEMBAHASAN}

Hasil dari beberapa tahapan pelaksanaan pada kegiatan pengabdian kepada masyarakat yaitu tahap pra pelaksanaan sudah dilakukan pertemuan dan kerjasama dengan pihak Puskesmas Aur Duri dan pihak Kelurahan Penyengat Rendah untuk pelaksanaan posyandu remaja dengan ditambahkan program plus KIE kesehatan reproduksi yang dilakukan secara rutin di posyandu remaja kelurahan Penyengat Rendah. Peningkatan pengetahuan kader tenatang KIE kesehatan reproduksi dilakukan dnegan teknik diskusi menggunakan metode Buzz Group. Adapun Dokumentasi kegiatan dapat dilihat pada gambar berikut :

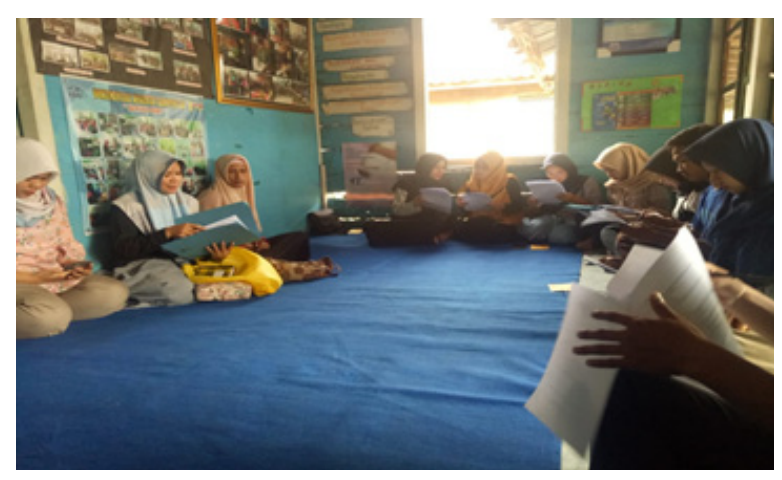

Gambar 1. Diskusi dan pemberian materi KIE Kespro Remaja

Tahap Pelaksanaan dilakukan dengan pemberian materi/informasi tentang KIE kesehatan reproduksi pada kader remaja yang menjadi sasaran sehingga dapat meningkatkan pengetahuan dan informasi kepada kader remaja tentang permasalahan remaja yang dihadapi dan mengetahui cara menghadapi masalah tersebut, memberikan materi melalui diskusi menggunakan metode Buzz Group sehingga semua materi tersampaikan dengan baik dan menyenangkan dan memberikan pelatihan tentang praktik Komunikasi Informasi dan Edukasi (KIE) kesehatan 
GEMASSIKA: Jurnal Pengabdian Kepada Masyarakat

Vol. 4 No. 2 November 2020

reproduksi yang bertujuan agar kader remaja mampu menjadi seorang konselor sebaya. Sebelum dan sesudah pemberian materi dilakukan penilaian pengetahuan pre and post tes menggunakan kuesioner pengetahuan. Adapun hasilnya dapat dilihat pada tabel berikut :

Tabel 1. Pengetahuan Kader Remaja Sebelum dan Sesudah Pemberian Materi KIE Kespro

\begin{tabular}{lcccccc}
\hline Metode & Mean & $\mathrm{N}$ & Std Deviasi & Std Error Mean & Correlation & Sig \\
\hline Sebelum Buzz Group & 10.43 & 30 & 1.223 & .223 & .604 & 0.000 \\
Sesudah Buzz Group & 13.57 & 30 & 1.431 & .261 & & \\
\hline
\end{tabular}

Pada tabel terlihat adanya perubahan pengetahuan remaja sebelum dan sesudah pemberian materi.

Kegiatan pemberian materi tentang KIE kesehatan reproduksi membahas tentang Organ reproduksi laki-laki dan perempuan, bagaimana menjaga kebersihan organ reproduksi, mengenal penyakit pada organ reproduksi yang umum terjadi. Peserta kegiatan sebanyak 30 orang yang terdiri ari kader posyandu dan calon kader yang berminat mempelajari tentang kesehatan reproduksi dan posyandu remaja.

Penelitian studi kualitatif yang dilakukan Wratsangka, R (2015) menunjukkan bahwa remaja cenderung menginginkan konselor kespro berasal dari teman sebayanya atau orang tua yang berjiwa muda, mereka kurang tertarik jika konselor berasal dari guru atau dosennya.
Penelitian Thomée, S et.al (2016) yang melakukan analisis komparatif kualitatif terhadap klinik remaja, menunjukkan bahwa remaja lebih menyukai pelayanan dari 5 doamain yaitu dapat diakses, dapat diterima, adil, sesuai dan efektif.

Penelitian Mazur A, Decker et. al (2018) menunjukkan kurangnya konsistensi dalam alat dan indikator yang digunakan untuk mengukur pelayanan kesepro remaja. Tiga domain yang paling sering dinilai adalah aksesibilitas, karakteristik dan kompetensi staf, serta kerahasiaan dan privasi. Mayoritas indikator tidak khusus untuk kebutuhan kaum muda dan sering kali mencerminkan standar perawatan dasar, hasil penelitian menunjukkan perlunya standarisasi dan prioritas indikator untuk evaluasi program kespro remaja.

Penelitian Hawke, D et al (2019) menunjukkan bahwa layanan kesehatan mental yang ramah remaja mencakup 
layanan terpadu, inklusif, rahasia, dan aman, didukung oleh ruangan konseling yang cerah, nyaman, lingkungan informasional dan penyedia layanan dengan keterampilan komunikasi dan konseling yang tepat; lokasi yang dapat diakses, waktu tunggu minimal dan pendekatan individual dan inovatif.

Banyaknya metode pendekatan terhadap remaja juga sebaiknya didukung oleh konselor yang ramah remaja. Metode diskusi Buzz group merupakan alat untuk membagi kelompok diskusi besar menjadi kelompokkelompok kecil. Ada dua jenis diskusi yang digunakan dalam menerapkan metode Buzz group yaitu pertama, teknik membagi kelompok asal menjadi kelompok buzz yang terdiri atas 10 sampai 15 orang, bila kelompok asal anggotanya berjumlah 30 orang atau lebih. Sekretaris membuat catatan tentang ide-ide yang disarankan oleh anggota kelompok dan menyiapkan kesimpulan yang akan disampaikan kepada kelompok besar setelah diskusi Buzz group selesai. Kemudian sekretaris tiap kelompok, diminta untuk melaporkan hasil sebelum dibuka diskusi kelompok umum. Waktu yang dibutuhkan untuk diskusi Buzz group berkisar 10-20 menit tergantung pada topik yang dibicarakan.

Berikut ini adalah gambar peserta kegiatan dapat dilihat pada gambar 2 berikut :

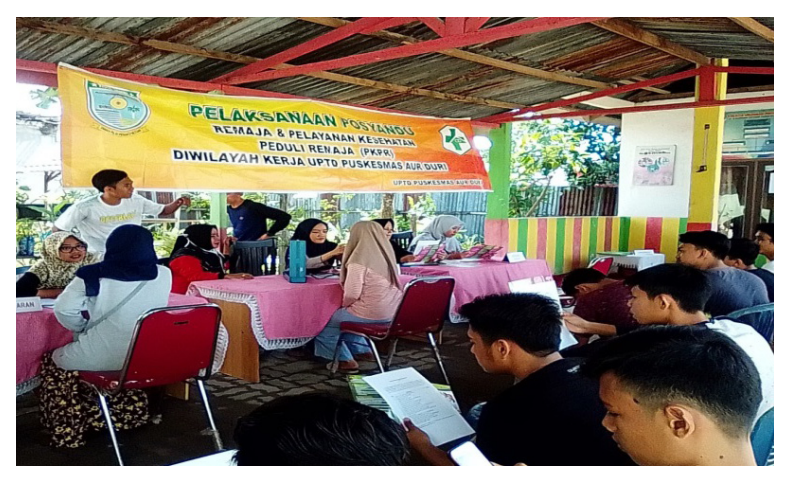

Gambar 2. Kegiatan Posyandu Remaja

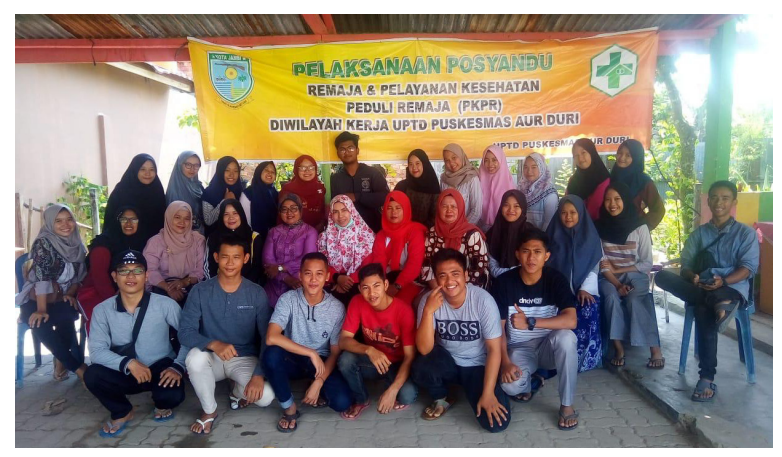

Gambar 3. Peserta Pelatihan KIE Kespro di Posyandu Remaja

Praktik KIE dilakukan dengan melihat kemampuan peserta dalam memberikan konseling kepada sasaran remaja dapat dilihat pada gambar berikut :

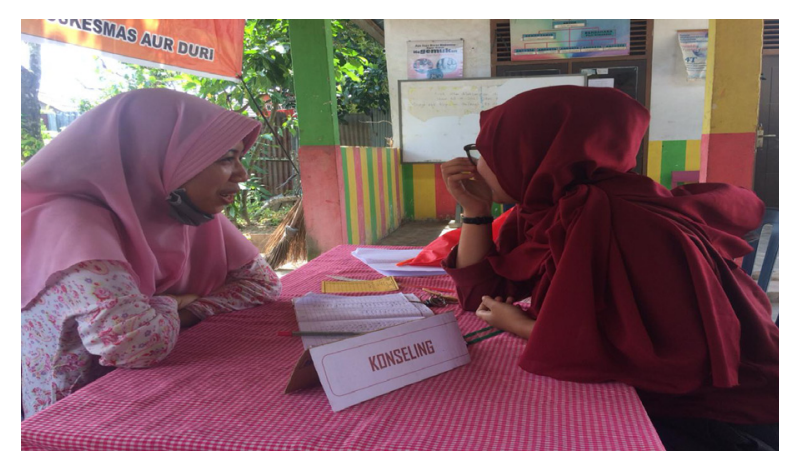

Gambar 4. Praktik Kegiatan KIE Kespro Remaja 
GEMASSIKA: Jurnal Pengabdian Kepada Masyarakat

Vol. 4 No. 2 November 2020

Tahap Pasca Pelaksanaan yaitu mengevaluasi pemahaman pengetahuan kader remaja tentang materi yang disampaikan dan mengevaluasi ketrampilan remaja dalam memberikan KIE kesehatan reproduksi terhadap teman sebayanya melalui tanya jawab dan penyampaian pesan kesan remaja. Kader remaja merasakan bahwa kegiatan ini dapat menambah pengetahuannya tentang kesehatan reproduksi yang sebelumnya mereka anggap tabu unuk dibahas, bagi kader mereka lebih merasakan percaya diri dalam menghadapi remaja yang akan melakukan konseling kepada mereka. Kegiatan ini dapat dilihat pada gambar berikut :

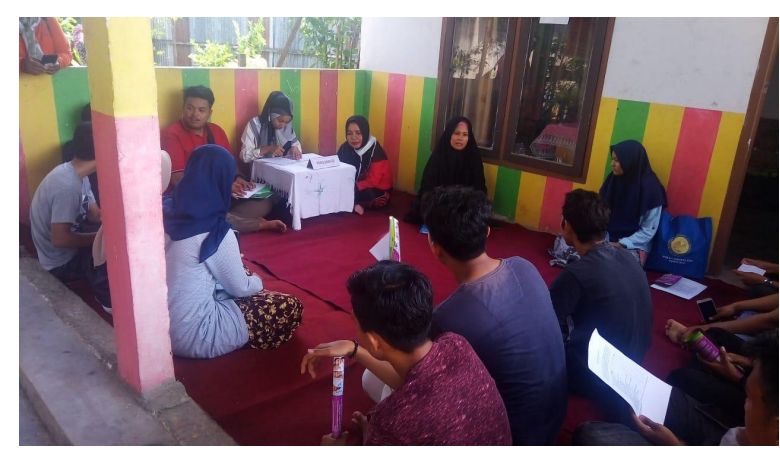

Gambar 5. Evaluasi Pasca Pelaksanaan

Berbagai metode dalam pemberian pendidikan kesehatan antara lain diskusi, ceramah, tanya jawab, konselor sebaya, curah pendapat dan lain-lain. Pada kelompok remaja khususnya di puskesmas PKPR (Pelayanan Kesehatan Peduli Remaja) metode yang paling sering digunakan adalah konselor sebaya dimana mereka dalam kelompok umur yang sama saling memberikan informasi seputar kesehatan reproduksi kepada teman sebayanya sehingga mereka bisa saling terbuka bercerita tentang masalah kesehatan reproduksinya (Kemenkes, 2015).

Berdasarkan beberapa hasil penelitian, menunjukkan bahwa Keunggulan luaran yaitu terlaksananya sosialisasi program posyandu remaja plus KIE kesehatan reproduksi, remaja memiliki rasa percaya diri dalam menjalankan tugasnya sebagai kader posyandu yang dapat menjadi konselor bagi teman teman sebayanya. Akan tetapi menurut Hawke et. al (2019) bahwa hal ini juga didukung oleh suasana konseling yang nyaman dan privacy serta konselor yang ramah remaja.

Adapun kelemahan luaran yaitu keterbatasan waktu penyampaian materi dikarenakan remaja dan kader remaja harus menjalankan kegiatan mereka di sekolah, sehingga kegiatan ini dilakukan sebanyak 2 kali kegiatan dan waktu yang disepakati oleh remaja yaitu hari sabtu siang setelah pulang sekolah.

\section{KESIMPULAN DAN SARAN}

Kegiatan pengabdian masyarakat ini dapat disimpulkan bahwa tingkat ketercapaian target sudah tercapai dengan baik, ketepatan masalah dengan metode yang diterapkan sudah cukup dan kader remaja merasakan 